\title{
High-Resolution Continuum-source Atomic Absorption Spectrometry - What Can We Expect?
}

\author{
Bernhard Welz ${ }^{*, a}$, Helmut Becker-Ross ${ }^{b}$, Stefan Florek ${ }^{b}$, Uwe Heitmann $^{b}$ and Maria Goreti R. Vale \\ ${ }^{a}$ Departamento de Química, Universidade Federal de Santa Catarina, 88040-900 Florianópolis - SC, Brazil \\ ${ }^{b}$ ISAS Berlin, Albert-Einstein-Strasse 9, 12489 Berlin, Germany \\ ${ }^{c}$ Instituto de Química, Universidade Federal do Rio Grande do Sul, 91501-970 Porto Alegre - RS, Brazil
}

\begin{abstract}
Um novo conceito instrumental vem sendo desenvolvido para espectrometria de absorção atômica (AAS), usando como fonte de radiação uma lâmpada de xenônio de alta intensidade, um monocromador double-echelle e um dispositivo com arranjo de carga acoplada como detector, permitindo uma resolução de $\sim 2$ pm por pixel. Entre as principais vantagens do sistema estão: i) uma melhora na razão sinal/ruído devido à elevada intensidade da fonte de radiação, resultando em melhor precisão e limites de detecção; ii) pelo mesmo motivo, não há mais linhas "fracas", portanto raias secundárias podem ser usadas sem comprometimentos; iii) novos elementos podem ser determinados, para os quais fontes de radiação ainda não são disponíveis; iv) toda a região espectral nas vizinhanças da raia analítica torna-se "visível", possibilitando muito mais informações do que as obtidas por instrumentos convencionais de AAS; v) a detecção com arranjo de carga acoplada permiti uma correção simultânea real da radiação de fundo nas proximidades da raia analítica; vi) o software possibilita a armazenagem de espectros de referência, por exemplo, de espectro de absorção molecular com estruturas rotacionais finas, e a subseqüente subtração deste do espectro de uma amostra, usando-se o algoritmo dos mínimos quadrados, sendo assim possível a correção de fundo estruturado mesmo sob a raia analítica; vii) embora ainda não disponível, se um detector bidimensional apropriado for usado o sistema permitirá em AAS medidas simultâneas multielementares, prática comum em espectrometria de emissão ótica; (viii) finalmente, experimentos preliminares vêm indicando que o novo instrumental poderá resultar em um melhor desempenho analítico na determinação de elementos traço em matrizes complexas.
\end{abstract}

A new instrumental concept has been developed for atomic absorption spectrometry (AAS), using a high-intensity xenon short-arc lamp as continuum radiation source, a high-resolution doubleechelle monochromator and a CCD array detector, providing a resolution of $\sim 2 \mathrm{pm}$ per pixel. Among the major advantages of the system are: i) an improved signal-to-noise ratio because of the high intensity of the radiation source, resulting in improved photometric precision and detection limits; ii) for the same reason, there are no more 'weak' lines, i.e. secondary lines can be used without compromises; iii) new elements might be determined, for which no radiation source has been available; iv) the entire spectral environment around the analytical line becomes 'visible', giving a lot more information than current AAS instruments; v) the CCD array detector allows a truly simultaneous background correction close to the analytical line; vi) the software is capable of storing reference spectra, e.g. of a molecular absorption with rotational fine structure, and of subtracting such spectra from the spectra recorded for a sample, using a least squares algorithm; vii) although not yet realized, the system makes possible a truly simultaneous multi-element AAS measurement when an appropriate two-dimensional detector is used, as is already common practice in optical emission spectrometry; vii) preliminary experiments have indicated that the instrumental concept could result in a more rugged analytical performance in the determination of trace elements in complex matrices.

Keywords: continuum-source atomic absorption spectrometry, high-resolution atomic absorption spectrometry, spectral interferences, simultaneous background correction, three-dimensional spectrometry, thallium determination, sediment analysis

*e-mail: welz@qmc.ufsc.br 


\section{Introduction}

The first experiments on the 'line reversal' of alkali and alkaline earth spectra, carried out by Kirchhoff and Bunsen $^{1,2}$ in the second half of the $19^{\text {th }}$ century, in which the basic relationship between absorption and emission of radiation was established, were carried out using a light source that emitted a spectral continuum in the visible range, as this was the only type of radiation source available at that time. Other spectroscopists, such as Lockyer ${ }^{3}$, worked with similar arrangements, using equipment available at that time, as shown in Figure 1. Soon after these early investigations, atomic absorption was essentially forgotten, and optical emission spectroscopy (OES) became the technique of choice for the analysis of the elemental composition of a variety of materials, particularly of metallurgical samples.

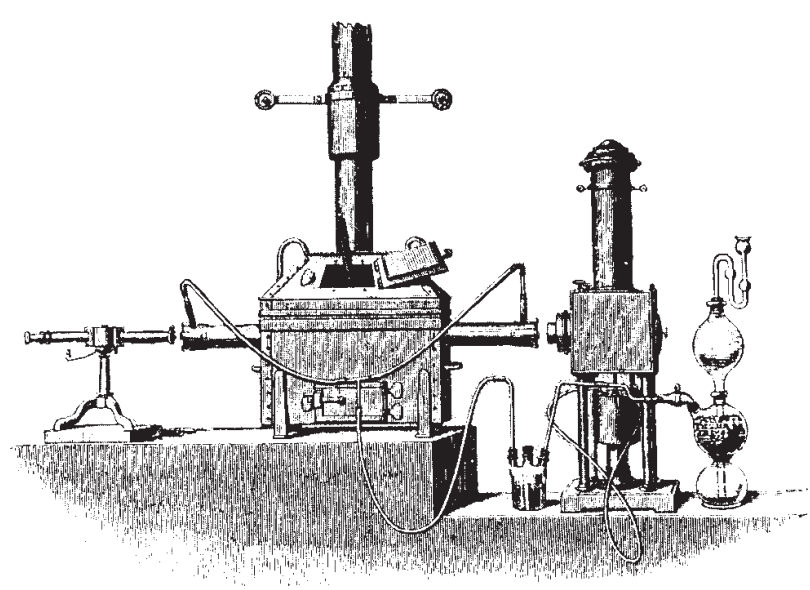

Figure 1. Apparatus used by Lockyer ${ }^{3}$ for measuring atomic absorption. The atomizer was an iron tube mounted in a coal-fired furnace; hydrogen was generated in a Kipp's apparatus to provide a reducing atmosphere in the tube; the light source is to the right and a spectroscope is to the left.

In 1952, Alan Walsh, who had been working on the spectrochemical analysis of metals for seven years, and in molecular spectroscopy for another six years, began to wonder why molecular spectra were usually obtained in absorption, and atomic spectra in emission ${ }^{4}$. The result of this musing was that there appeared to be no good reason for neglecting atomic absorption spectra. On the contrary, they appeared to offer many vital advantages over atomic emission spectra; hence, he started his first experiments with atomic absorption spectrometry (AAS). In the course of his preliminary investigations Walsh discussed the problems of recording atomic absorption spectra of flames with a continuum source and concluded that a resolution of about 2 pm would be required, which was well beyond the best spectrometer available in his laboratory at that time. He therefore concluded that "one of the main difficulties is due to the fact that the relations between absorption and concentration depend on the resolution of the spectrograph, and on whether one measures peak absorption or total absorption as given by the area under the absorption/wavelength curve." And after some further experiments in which he tried to determine copper using a continuous source, he concluded: "It is thought that this (poor sensitivity) is due to the low resolution of the Littrow spectrograph and to the excessive amount of scattered light at low wavelengths. It is hoped to overcome this difficulty by using a hollow-cathode lamp (copper cathode) as a source. This will emit sharp lines and a low resolution spectrometer will then be sufficient." ${ }^{4}$

This means that at the time when AAS was 're-invented', developed and proposed as a technique for the determination of trace elements in a variety of matrices, ${ }^{5}$ the only practical way was to use spectral line sources in order to obtain the required resolution that could not be provided by the monochromators available at that time. All commercial AAS instruments over the next half century followed the same principle of using line sources, which emitted a spectrum of the element of interest with narrow half-width in order to obtain the necessary resolution, and a low-resolution monochromator that only separated the analytical line from other lines emitted by the radiation source. Continuum sources (CS), such as deuterium arc lamps, were only used as a second source in addition to the line source (LS) to correct for background absorption. ${ }^{6}$ This obviously made LS AAS a one-element-at-a-time technique, which was in contrast to OES techniques, and has always been considered as one of the major disadvantages of AAS.

But the idea of using a CS as a primary radiation source for AAS was never forgotten, and there are many famous spectroscopists among those who worked in that field. However, substitution of a LS for a CS, without changing the rest of the instrument, is not a reasonable approach. The instability of the most intense CS, i.e. xenon arc lamps, gives noisy baselines and poor detection limits. Medium resolution monochromators, which are ideal for isolating LS emission lines, provide a spectral bandwidth that is too large for use with a CS, resulting in poor sensitivity and specificity, non-linear calibration curves and greater susceptibility to spectral interferences. In addition, the intensity of most CS decreases dramatically below 280 $\mathrm{nm}$; consequently, the use of a CS for AAS requires redesign of the whole instrument. ${ }^{7}$

A variety of instrumental designs have been explored 
for CS AAS, and the main challenges were to obtain sensitivities, detection limits and calibration ranges comparable to LS AAS. Sensitivity was initially enhanced by the use of multi-pass absorption cells. ${ }^{89}$ However, it became obvious very soon that the best approach was not to recover lost sensitivity, but to avoid the loss of sensitivity by using a high resolution spectrometer to provide the narrow analytical bandwidth previously supplied by the LS. ${ }^{10-17}$ In addition it was necessary to minimize the flicker noise of the xenon arc lamp in order to obtain detection limits comparable to those of LS AAS. This was accomplished using wavelength modulation with phasesensitive detection. ${ }^{10,13-19}$ Wavelength modulation has been implemented using quartz refractor plates, ${ }^{13,14,18,19}$ oscillating étalons ${ }^{10}$ and, ultimately, array detectors. ${ }^{15-17}$ The linearity of the calibration graph is primarily determined by the spectral bandwidth if the analytical measurement is carried out with a continuum source, hence echelles and interferometers provided the best linearity. ${ }^{11,13}$

In a review article entitled 'atomic absorption spectrometry - has it gone or where is it going?' Hieftje, ${ }^{20}$ back in 1989, made a literature survey and concluded that AAS is "on its way out as an analytical technique. With the current rapid growth in inductively coupled plasma (ICP) OES and ICP mass spectrometry... AAS is heading for difficult times. If current trends continue, I would not be surprised to see the removal of commercial AAS instruments from the marketplace by the year 2000." Clearly, this forecast did not become true, but another forecast that Hieftje made in the same article could nowadays be considered visionary, as he wrote: "Clearly, for AAS to remain viable in the face of strong competition from alternative techniques will require novel instrumentation or approaches. Among the novel concepts that have been introduced are those involving continuum sources and high-resolution spectral-sorting devices... and entirely new detection approaches."

This 'entirely new approach' appears to have been realized by Becker-Ross and co-workers, ${ }^{21-27}$ who decided to design a new spectrometer, taking into account the special requirements of CS AAS. The spectrometer consists of a high-intensity xenon short-arc lamp as CS, a compact double echelle monochromator with a resolving power of $\lambda / \Delta \lambda \approx 110,000$ as the spectral sorting device, and a linear charge coupled device (CCD) array detector with a resolution of about $2 \mathrm{pm}$ per pixel in the far UV range. Preliminary results obtained with this kind of equipment stimulated Harnly ${ }^{7}$ to predict a bright future for CS AAS: "Whereas, previously, CS AAS was striving for parity with LS AAS, it is now reasonable to state that it is CS AAS which is setting the standard."

\section{Instrumentation, Software and Data Processing}

For a theoretical analysis of the detection of small absorbances two cases have to be taken into account: as long as the limiting noise of the signal is given by the detector noise, an increase in spectral bandwidth of the spectrometer implies an improvement in the limit of detection (LOD). In contrast, if the noise of the signal is dominated by the photon shot noise, the LOD should become independent of the spectral bandwidth. In this case the spectral bandwidth of the spectrometer should be chosen equal to the bandwidth of the absorption line to avoid spectral interferences. Becker-Ross et al. ${ }^{24}$ measured the full width at half maximum (FWHM) for a variety of elements beginning in the far UV up to the visible range, and the correlation between FWHM and wavelength, which is shown in Figure 2, suggested that a resolving power of $\lambda / \Delta \lambda_{\text {instr }} \approx 110,000$ would be sufficient for the majority of elements for CS AAS, resulting in an optimum signal-to-noise $(\mathrm{S} / \mathrm{N})$ ratio and linearity of the calibration graph. The instrumental concept that resulted from these considerations has been described in detail by Heitmann et $a l .^{25}$ and is shown schematically in Figure 3. It consists of a Perkin-Elmer Model 4100ZL atomic absorption spectrometer (Bodenseewerk Perkin-Elmer GmbH, Überlingen, Germany), from which the entire optical compartment including detector and associated controls had been removed and replaced by a double echelle monochromator (DEMON $)^{23,28}$ with a focal length of 302 $\mathrm{mm}$ and a spectral resolution of $\lambda / \Delta \lambda_{\text {instr }} \approx 110,000$. In more recent experiments an AAS6 Vario atomic absorption spectrometer (Analytik Jena AG, Jena, Germany) has been

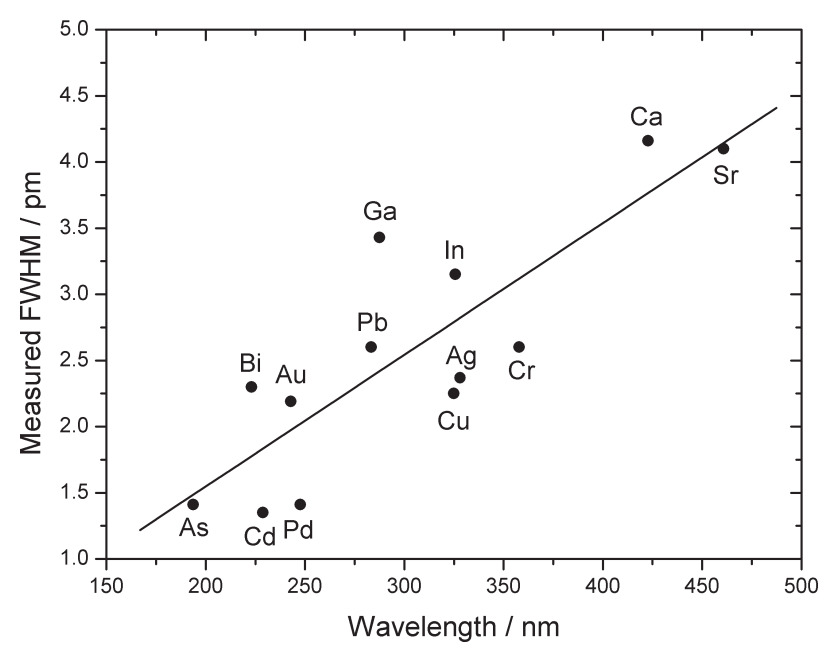

Figure 2. Correlation between the full width at half maximum (FWHM), measured for a number of elements, and the wavelength of their analytical lines. 


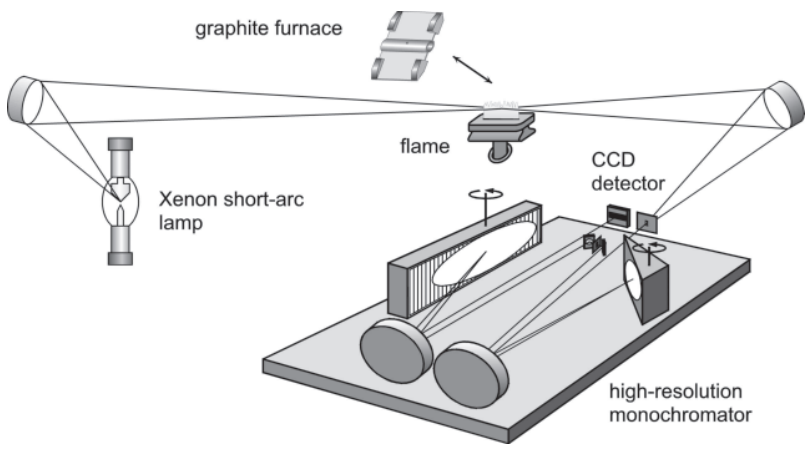

Figure 3. Instrumental concept for high-resolution CS AAS.

used as the basis for the same optical setup. The earlier system, based on the Perkin-Elmer Model 4100ZL was equipped with the transversely heated graphite furnace module of that instrument, which was controlled by the original software. The modified AAS6 Vario could alternately be used with a transversely heated graphite tube atomizer or with a flame atomizer.

A xenon short-arc lamp XBO 301 (GLE, Berlin, Germany) with a nominal power of $300 \mathrm{~W}$ and an electrode distance of $\leq 1 \mathrm{~mm}$ (pressure of the cold lamp 17 bar) was used as the continuum radiation source. An L $172 \mathrm{UV}$-sensitive linear CCD array detector with 512 pixels, $23 \mu \mathrm{m}$ x $480 \mu \mathrm{m}$ (WF, Berlin, Germany) was used, resulting in an instrumental bandwidth of $1.8 \mathrm{pm} /$ pixel at $200 \mathrm{~nm}$ (with a slit width of $23 \mu \mathrm{m}$ ), and of about $2.65 \mathrm{pm} /$ pixel at $276.787 \mathrm{~nm}$, the wavelength of thallium, which was used for most of the experiments in this work. The integrated absorbance spectrum around the Cd resonance line at $228.802 \mathrm{~nm}$ of the three-dimensional CS AAS measurement with a spectral resolution of $2.3 \mathrm{pm} /$ pixel is shown in Figure 4 in order to demonstrate the performance of the system.

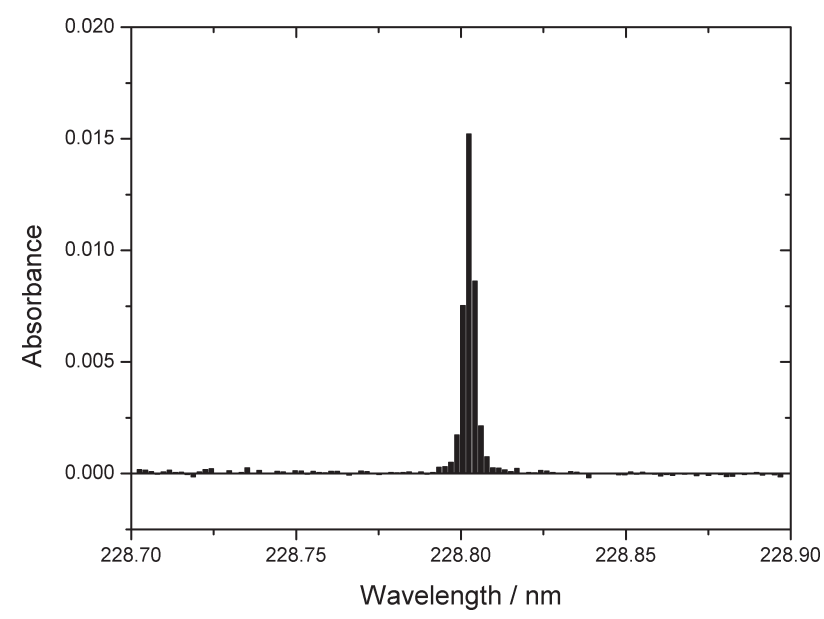

Figure 4. Integrated absorbance spectrum for $40 \mu \mathrm{g} / \mathrm{L} \mathrm{Cd}$ recorded in the environment of the resonance line at $228.802 \pm 0.1 \mathrm{~nm}$.
The system was controlled by an $80486 / 100 \mathrm{MHz}$ personal computer running an in-house developed data acquisition program. The system allows recording of up to 60 spectra per second. One of the important features of the software is the automatic correction for all 'events' that are 'continuous' within the observed spectral range, i.e. that influence all pixels of the CCD array in the same way. The most important assumption for this kind of correction is that variations in the intensity of the CS as well as continuous background absorption, are perfectly correlated in time within the small spectral range of approximately $0.3 \mathrm{~nm}$ that is recorded. The simultaneous recording is guaranteed by the use of the linear CCD array with 512 photosensitive pixels that simultaneously convert the incident photons into photoelectrons and store them within the illumination time. The stored charge pattern is transferred for all pixels simultaneously into the readout register, and subsequently converted into chargeproportional voltage impulses by the on-chip amplifier, which are then amplified and digitalized. The next irradiation of the photosensitive pixels is already going on during this readout; this way it is guaranteed that proportional variations in the intensity are precisely converted into proportional changes in the digitalized signals for each individual pixel.

Figure 5a,b shows the performance of this proportionality correction system using the example of raw and corrected signals recorded during the atomization stage of a marine sediment reference material, measured at the wavelength of $\mathrm{Tl}$ around $276.787 \mathrm{~nm}$. Figure 5a shows a very pronounced baseline fluctuation during the first $2.5 \mathrm{~s}$ of the atomization stage, due to an unusually high flicker noise of the xenon arc radiation source, followed by background absorption between about $3 \mathrm{~s}$ and $3.5 \mathrm{~s}$, which is superimposed by the flicker noise of the CS. The pixel for the measurement of the $\mathrm{Tl}$ line is marked in black. This stage in the signal evaluation is usually not exhibited, but the example was chosen deliberately in order to demonstrate that the system works perfectly even under such a 'worst-case' situation. After correction for all 'continuous events', the baseline distortion due to the lamp flicker noise as well as the continuous background absorption has disappeared, as shown in Figure 5b, and only the $\mathrm{Tl}$ absorption line (marked with a black line) and a molecular absorption with a rotational fine structure is left. Analytical details involved in this example will be discussed later.

\section{The Continuum Source}

The most obvious advantage of using a CS in AAS is that only one single radiation source is required for all 


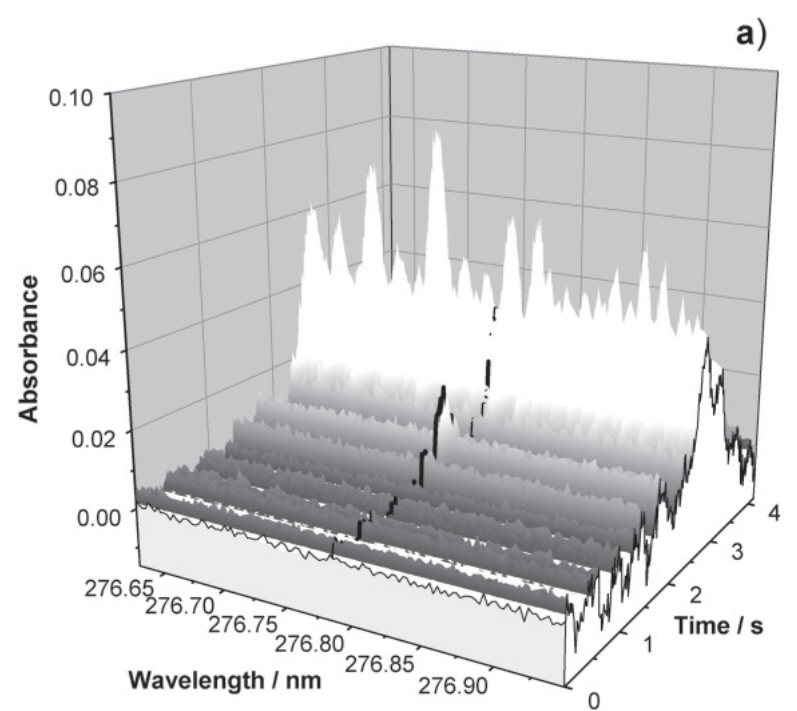

b)

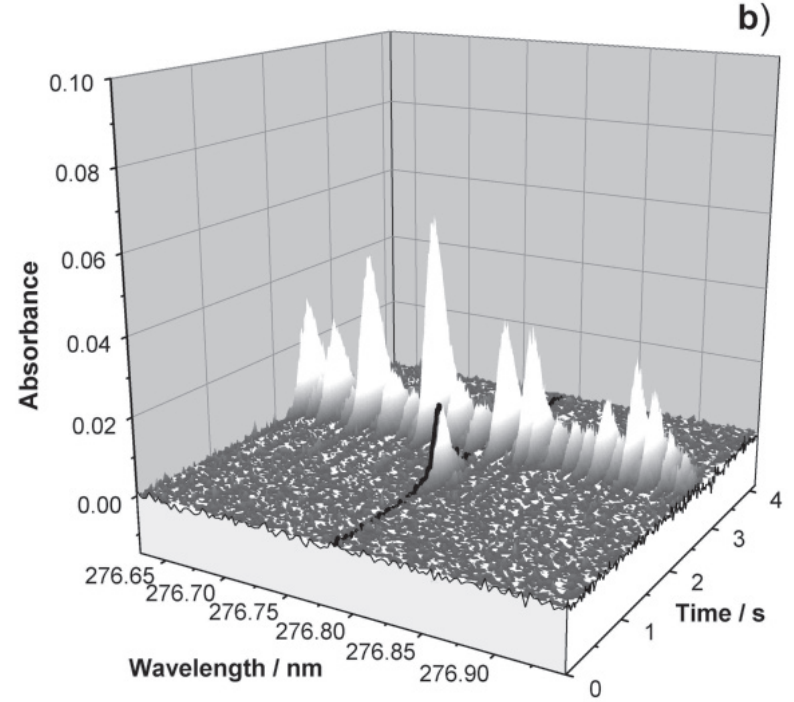

Figure 5. Principle of correction for flicker noise of the radiation source and for continuous background absorption in CS AAS, using the example of PACS - 2 marine sediment reference material around the resonance line for $\mathrm{Tl}$ at $276.787 \mathrm{~nm}$; atomization temperature $1650{ }^{\circ} \mathrm{C}$; a) absorbance over time and wavelength before any correction; b) after correction for all events that were recorded identically by all pixels.

elements and lines, which is a great simplification compared to LS AAS, and also a significant cost saving when more than just a few elements have to be determined. Another general advantage, although not realized in the instrument described here, is that the CS in principle makes AAS a truly simultaneous multi-element technique, as the analytical lines of all elements are available in the primary radiation source. All that is required in order to realize this feature is the development of a two-dimensional CCD detector that covers the spectral range of AAS, and that, for example, contains a series of linear arrays, one for each element or wavelength of interest. Obviously, such a detector would be expensive, but similar detectors are in use already in echelle spectrometers for ICP OES. ${ }^{29-31}$ However, the only functional multi-element CS AAS instrument built up until now is that described by Harnly et al. ${ }^{14}$ back in 1979.

Although it had been claimed over decades that the LS used in AAS had a significantly higher radiation intensity than CS within the small spectral interval of an absorption line, this is no longer true for the xenon short arc lamp used in the present instrument. In contrast, the radiation intensity of this CS is at least one or two orders of magnitude higher for most elements than that of the corresponding LS, including electrodeless discharge lamps and 'superlamps'. As in AAS, in a first approximation, the noise is inversely proportional to the square root of the radiation intensity, an improvement in the latter usually results in a corresponding improvement in the photometric precision and LOD. This is demonstrated in Table 1, which shows for a number of elements LODs obtained with CS AAS, using an air-acetylene flame.

Table 1. Examples of detection limits (the analyte concentration in $\mu \mathrm{g} \mathrm{L} \mathrm{L}^{-1}$, corresponding to three times the standard deviation of a blank) obtained with CS AAS using an air-acetylene flame.

\begin{tabular}{lcc}
\hline Element & Wavelength / nm & LOD / $\mu \mathrm{g} \mathrm{L}^{-1}$ \\
\hline $\mathrm{Ag}$ & 328.1 & 1.2 \\
$\mathrm{Au}$ & 242.8 & 3.2 \\
$\mathrm{Bi}$ & 223.1 & 10 \\
$\mathrm{Cd}$ & 228.8 & 0.8 \\
$\mathrm{Co}$ & 240.7 & 1.8 \\
$\mathrm{Cr}$ & 357.9 & 1.8 \\
$\mathrm{Cu}$ & 324.8 & 1.2 \\
$\mathrm{Fe}$ & 248.3 & 1.8 \\
$\mathrm{Ga}$ & 287.4 & 45 \\
$\mathrm{In}$ & 325.6 & 10 \\
$\mathrm{Ir}$ & 208.9 & 760 \\
$\mathrm{Li}$ & 670.8 & 0.12 \\
$\mathrm{Mg}$ & 285.2 & 0.15 \\
$\mathrm{Mn}$ & 279.5 & 0.6 \\
$\mathrm{Ni}$ & 232.0 & 2.5 \\
$\mathrm{~Pb}$ & 217.0 & 10 \\
$\mathrm{Pd}$ & 247.6 & 4 \\
$\mathrm{Pt}$ & 265.9 & 30 \\
$\mathrm{Rh}$ & 343.5 & 6 \\
$\mathrm{Ru}$ & 349.9 & 40 \\
$\mathrm{Sb}$ & 217.6 & 30 \\
$\mathrm{Te}$ & 214.3 & 30 \\
$\mathrm{Tl}$ & 276.8 & 6 \\
$\mathrm{Zn}$ & 213.9 & 1.4 \\
\hline
\end{tabular}

The improvement in the S/N ratio and LOD depends on the increase in radiation intensity brought about by the $\mathrm{CS}$ at the specific analytical wavelength used for the measurement. As the CS has roughly the same intensity 
over the spectral range of interest in AAS, the decisive factor is the radiation intensity of the LS, and the LODs in Table 1 are significantly better than those published for $\mathrm{LS} \mathrm{AAS}^{32}$ for elements with relatively weak analytical lines. This leads directly to another advantage of CS AAS, as it is well known that the lines emitted by a LS, such as a hollow cathode lamp (HCL), can have significantly different intensities. In the case of $\mathrm{Pb}$, for example, the resonance line at $283.3 \mathrm{~nm}$ is usually preferred over that at $217.0 \mathrm{~nm}$ because of its significantly better $\mathrm{S} / \mathrm{N}$ ratio, although the latter one is more than a factor of two more sensitive. This problem of 'weak and noisy lines' often becomes dominant when 'less sensitive, secondary lines' are investigated for the determination of higher analyte concentration. Obviously, this problem of 'weak' lines disappears when a CS with the described characteristics is used as the primary source, hence, secondary lines can be used without compromises and without a sacrifice of precision.

Furthermore, as literally any line over the entire spectral range is available from a CS, it is possible to determine elements with CS AAS for which no LS are available. Although there are not many elements for which that is the case, there are, for example, some radioactive elements, for which it is almost impossible to produce and store an HCL. Another example, although somewhat exotic, is the determination of isotope ratios for a few elements up to an atomic number of $Z=40$ as, for these elements, the lines for the heavier isotope are shifted far enough towards shorter wavelengths to separate them spectroscopically. The best known example for that application is the ${ }^{6} \mathrm{Li} /{ }^{7} \mathrm{Li}$ ratio, which has been determined by several groups by AAS, using lithium isotope lamps, ${ }^{33-36}$ which, however, are not commercially available.

\section{The Echelle Spectrometer with CCD Array Detector}

The first and most obvious advantage of the instrumental concept discussed here, consisting of a highresolution echelle monochromator and a linear CCD detector array, is the additional information about the spectral environment that becomes available. In the case of time-dependent signals, as they are produced in GF AAS, we literally obtain three-dimensional information, i.e. absorbance over time and over wavelength, as can be seen in the example of Figure 5. This clearly opens a new dimension for AAS that can be used in a variety of ways, such as for the optimization of temperature programs, as it is shown in Figure 6a,b, using again the example of the determination of thallium in marine sediments. ${ }^{37}$ With a temperature program that had been optimized previously for similar matrices, using an atomization temperature of $2400{ }^{\circ} \mathrm{C}$, the most outstanding feature, as shown in Figure 6a, was a strong absorption line at $276.752 \mathrm{~nm}$, which could be assigned to iron. This line would obviously not cause any problems in CS AAS, as it is well separated from the analyte line at $276.787 \mathrm{~nm}$, but it would certainly cause a spectral interference when conventional deuterium arc background correction is used. When the atomization temperature was lowered to $2000{ }^{\circ} \mathrm{C}$, the intensity of the iron absorption decreased significantly, as can be seen in Figure 6b, but a new set of (molecular) absorption lines appeared that was much less apparent (because of the different absorbance scale) at the higher atomization temperature. At an atomization temperature of $1650{ }^{\circ} \mathrm{C}$,
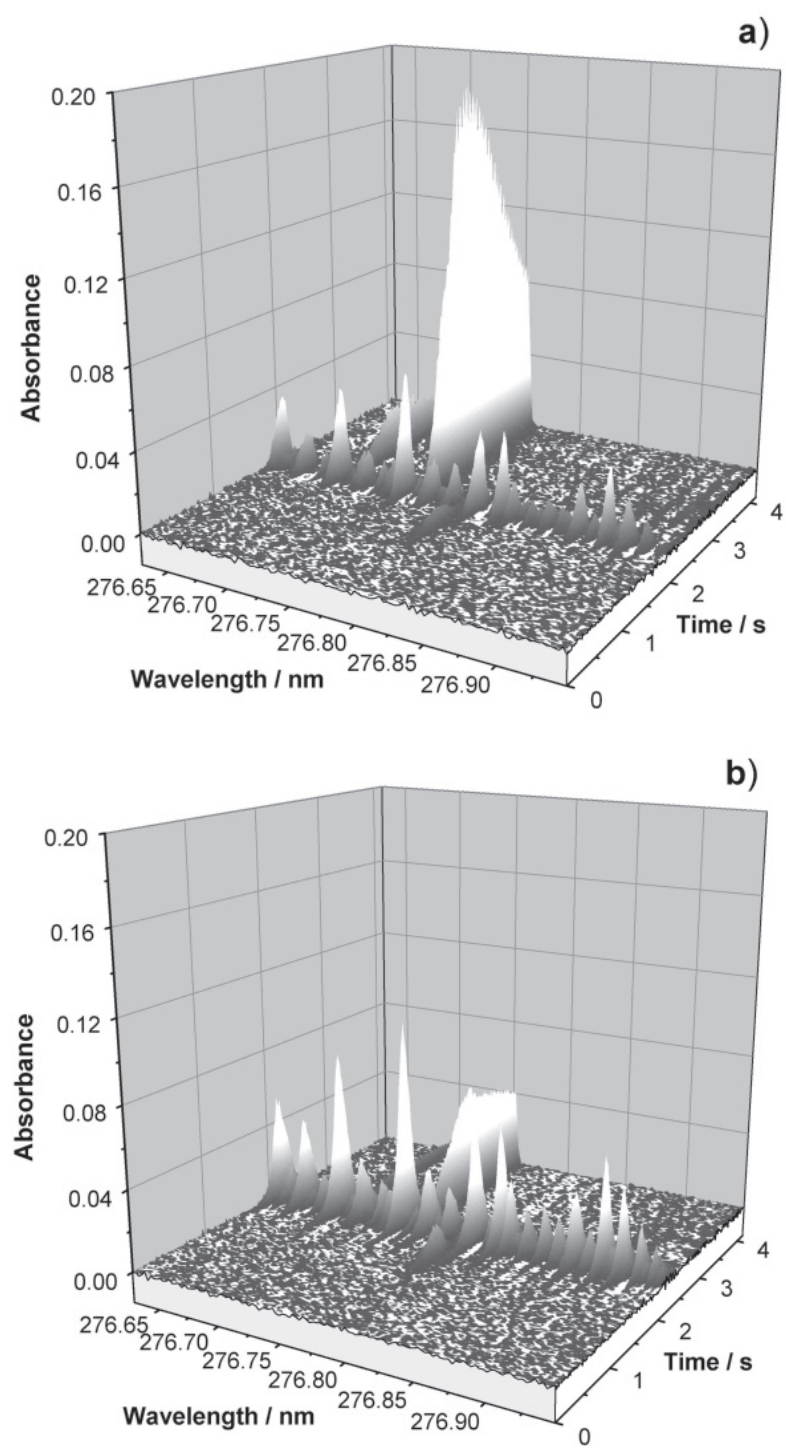

Figure 6. Absorbance signals obtained for $0.1 \mathrm{mg}$ PACS -2 marine sediment reference material at $276.787 \pm 0.16 \mathrm{~nm}$; a) atomization temperature $2400{ }^{\circ} \mathrm{C}$; b) atomization temperature $2000{ }^{\circ} \mathrm{C}$. 
the iron absorption disappeared completely, and the molecular structure, in addition to the analyte line, which appeared earlier in time, were the only features, as shown in Figure 5b. In high-resolution CS AAS, using this information, it would probably be sufficient to measure the absorbance with the pixel at the Tl line, and to exclude the molecular absorption by limiting the integration to a point in time before the molecular spectrum appears.

But obviously, there are a lot more opportunities available, mainly in the field of background correction, a traditional topic in AAS, particularly in GF AAS. The correction for continuous (within the wavelength range of the CCD array) background has been treated earlier, and is shown in Figure 5a,b. But with the CCD array detector, the same kind of background correction as is used in OES, i.e. close to the analytical line, is available as well. Any of the pixels of the CCD array, or a combination of them, can be used for a truly simultaneous background correction at any distance from the analytical line.

Yet another possibility for background correction in the case of a direct line overlap is shown in Figure 7 for the determination of $\mathrm{Zn}$ in iron using flame AAS. The iron line

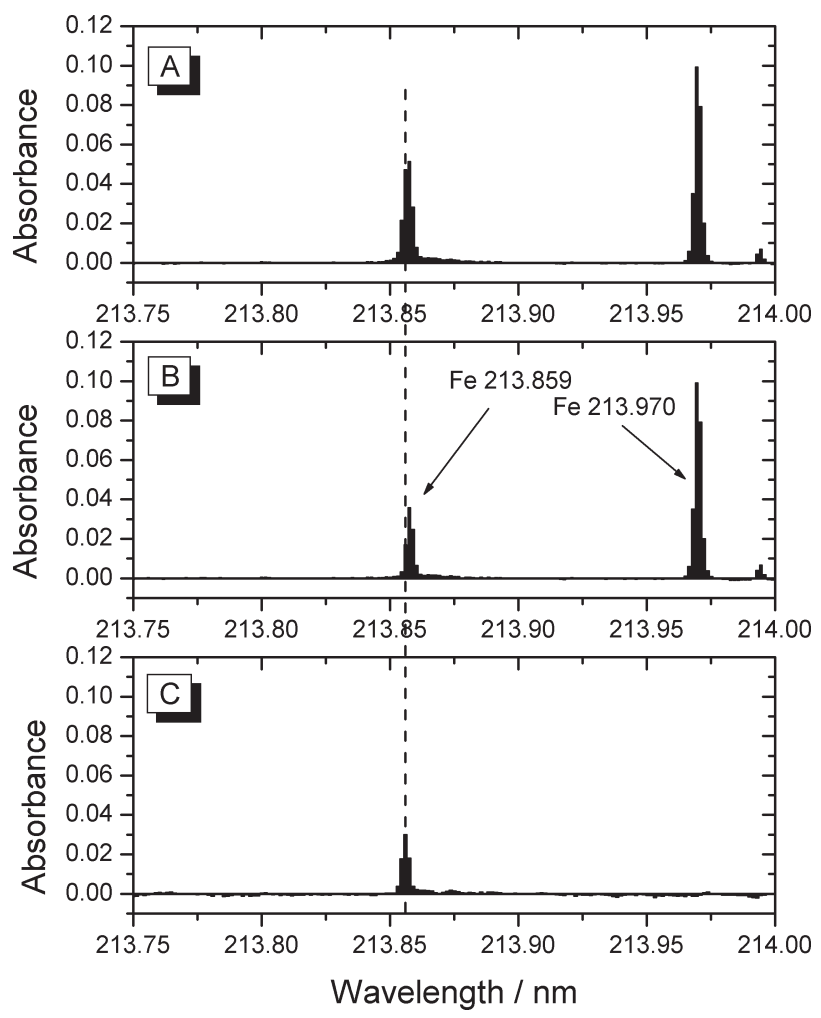

Figure 7. Least squares correction of a spectral interference due to line coincidence: determination of zinc $(0.3 \mathrm{mg} / \mathrm{L})$ in iron $(1000$ $\mathrm{mg} / \mathrm{L})$ using flame atomization; A) integrated absorbance spectrum for $\mathrm{Zn}$ in iron matrix without correction; B) integrated absorbance spectrum for iron alone, used for the correction; $C$ ) integrated absorbance spectrum for $\mathrm{Zn}$ in iron matrix after correction. at 213.859 cannot be completely resolved from the zinc resonance line at $213.856 \mathrm{~nm}$, resulting in a spectral interference using conventional flame AAS, with or without background correction. Even Zeeman-effect background correction cannot help, as both lines show similar Zeeman splitting in a magnetic field, making any correction impossible. Using CS AAS, a second iron line at 213.970 $\mathrm{nm}$ offers itself for correction purposes. As the absorbance ratio between the two iron lines will remain constant as long as both lines are within the linear range of calibration, it is sufficient to measure the absorbance of the Fe line at $213.970 \mathrm{~nm}$, calculate the corresponding absorbance at the $\mathrm{Zn}$ line at $213.856 \mathrm{~nm}$, and subtract that value from the absorbance measured for $\mathrm{Zn}$ at that line.

\section{Least Squares Background Correction}

Several options for background correction been discussed up to now, i.e., the automatic correction for all 'continuous events' that affect all pixels of the CCD array in the same way, and that correct for any background absorption that is continuous over the spectral range of ca. $0.3 \mathrm{~nm}$, even when it changes rapidly with time, as the measurement and correction is truly simultaneous. Background correction using adjacent pixels or lines has been discussed in the previous section and will not be repeated. But the software offers yet another possibility that is particularly aimed at molecular absorption with rotational fine structure, as it is typical for electron excitation spectra, and at line overlap with atomic lines. One of the best investigated examples for electron excitation spectra with rotational fine structure is the molecular absorption spectrum of PO, which is observed in GF AAS in the presence of high phosphate matrices (or modifiers). ${ }^{25,27}$ This kind of spectral interference cannot be handled at all by deuterium arc background correction or the so-called Smith-Hieftje background correction, ${ }^{38}$ using high-current pulsing of the radiation source, and even causes some problems in Zeeman-effect background correction. $^{32}$

In order to cope with this kind of interference, the instrument described here offers the possibility to measure model spectra and store them in the software. One or more of these spectra may then be subtracted from the spectrum measured for the actual sample, using a least squares algorithm. The mathematical procedure used in this case is a linear fit of the reference spectrum to every single sample spectrum. The reference spectrum is then increased or decreased by multiplication with a magnification factor. The differences between the reference spectrum and the sample spectrum, as well as their squares, are calculated 
pixel by pixel, and the sum of the square values over all pixels is added up. After that, the mentioned magnification factor is varied in order to minimize the sum of the squares or - in other words, to find the 'least squares'. Using this procedure, specifically that part of the structured background is eliminated that corresponds to the fine structure of the reference spectrum. A linear combination of more than one reference spectrum can be used with the same aim. This kind of background correction, although it is performed 'off-line' corrects for any structured background 'under' the line and simultaneously, although the correction is carried out after the measurement.

The example of $\mathrm{Tl}$ determination in a marine sediment sample, which has already been shown in part in Figure $5 a, b$, will be used to demonstrate the efficiency of this least squares background correction. The three-dimensional plot in Figure 5b shows the absorbance spectrum over time for $\mathrm{Tl}$ and for a matrix component after correction for continuous background absorption. As a strong correlation between the signal suppression for $\mathrm{Tl}$ and the sulfur content of the sediment had already been found with conventional GF AAS, ${ }^{39}$ it was suspected that the molecular absorption spectrum in Figure $5 \mathrm{~b}$ was part of the electron excitation spectrum of $\mathrm{SO}_{2}$. Hence, a reference spectrum was measured by atomizing $0.01 \mathrm{mg}$ of $\mathrm{KHSO}_{4}$ under the same conditions, which is shown in Figure 8a, and which obviously has great similarity with that in Figure $5 \mathrm{~b}$. After subtracting the two spectra using the abovedescribed least squares procedure, the spectrum shown in Figure $8 \mathrm{~b}$ was obtained, which exhibits only the atomic absorption signal of thallium, demonstrating that the molecular absorption spectrum was exclusively due to $\mathrm{SO}_{2}$, and no further correction was necessary. Similar results have been reported earlier, for example, for the determination of arsenic and selenium in human urine after subtracting the spectra of $\mathrm{PO}$ and $\mathrm{NaCl}$ in the case of As, and the spectra of $\mathrm{PO}$ and $\mathrm{NO}$ in the case of Se..$^{27}$ This least squares background correction clearly fulfills the 'dream of the spectrochemist', to 'look under the line', as illustrated in a drawing by (the late) Hans Massmann, one of the pioneers of GF AAS, shown in Figure 9.

\section{Analytical Applications}

The truly simultaneous correction for continuous background, which can follow even the fastest signals of GF AAS, the possibility to use any set of pixels near the analytical line for background correction and, particularly, the least squares background correction for structured molecular or atomic absorption obviously contribute to reduce the influence of spectral interferences on the analyte

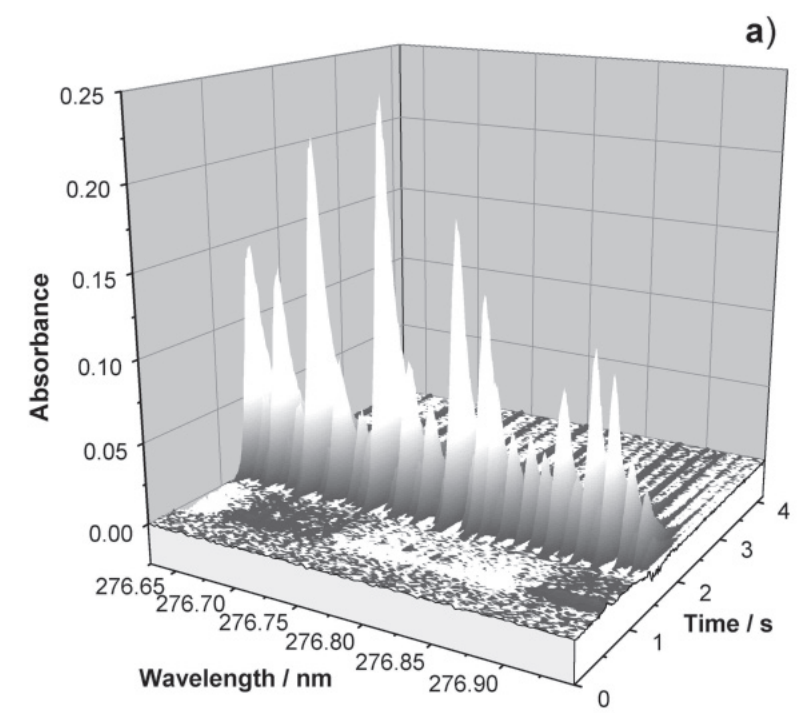

b)

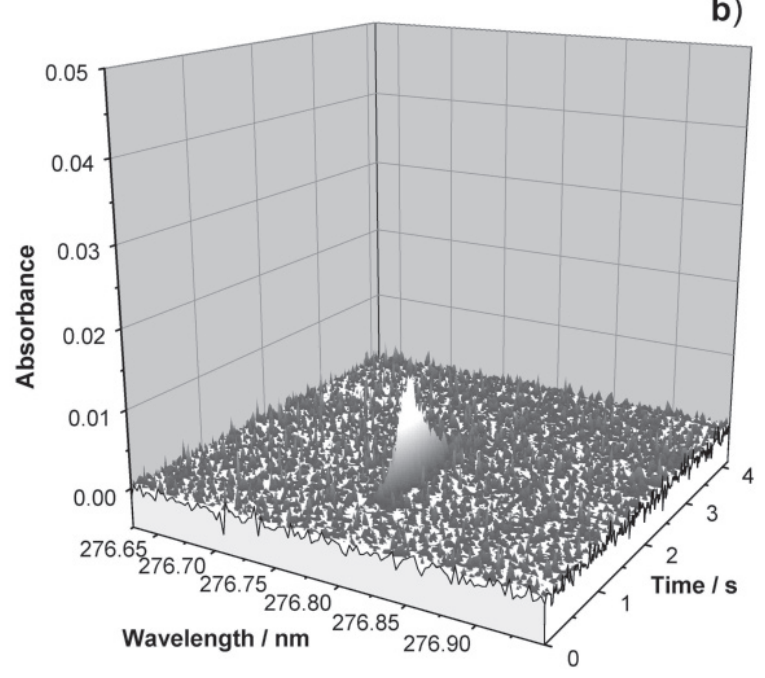

Figure 8. Least squares background correction for structured background; atomization temperature $1650{ }^{\circ} \mathrm{C}$; a) molecular absorption spectrum recorded during the vaporization of $10 \mu \mathrm{g} \mathrm{KHSO}_{4}$ at $276.787 \pm 0.16 \mathrm{~nm}$; b) residual absorbance spectrum for PACS -2 after subtracting the stored reference spectrum from the spectrum shown in Figure 5b.

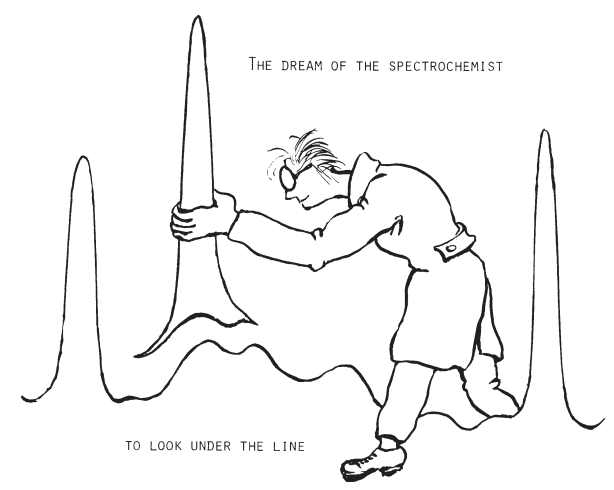

Figure 9. "The dream of the spectrochemist - to look under the line". Drawing by (the late) Hans Massmann (Institute for Spectrochemistry and Applied Spectroscopy, ISAS, Dortmund, Germany). 
signal close to zero. But besides the spectral interferences, there are non-spectral interferences, particularly in GFAAS in the presence of complex matrices, even when the stabilized temperature platform furnace (STPF) concept $t^{40}$ is applied. And $\mathrm{Tl}$ is an excellent example for that, as it is plagued by a notorious chloride interference due to the volatility and thermal stability of the monochloride $\mathrm{TlCl} .^{41}$ An additional complication in this case is that palladium, the most efficient chemical modifier, causes a spectral interference due to a line overlap at the most sensitive wavelength for $\mathrm{Tl}$, making the use of this modifier problematic in conventional GF AAS. ${ }^{41}$ Manning and Slavin ${ }^{42}$ have tried to avoid these problems by using a 'fast furnace' program with a very low pyrolysis temperature, at which $\mathrm{TlCl}$ is not yet volatilized (or no pyrolysis stage at all), no chemical modifier, and Zeemaneffect background correction in order to cope with the high background absorption as, with such a program, essentially the entire matrix is volatilized in the atomization stage.

We tried to follow the same procedure in earlier work for the determination of $\mathrm{Tl}$ in marine sediment reference materials and failed, as can be seen from the results in Table 2. ${ }^{39}$ Even Zeeman-effect background correction could apparently not cope with the complex matrix of these samples. Accurate results could be obtained only after a careful optimization of the temperature program and the modifiers, using a combination of ammonium nitrate to remove the bulk of the chloride and ruthenium to stabilize the analyte (Table 2). ${ }^{39}$ When the same experiments were repeated using CS AAS, essentially the same results were obtained using no modifier and a low pyrolysis temperature of $300{ }^{\circ} \mathrm{C}$, and with the modifier combination that had to be used for LS AAS with Zeemaneffect background correction. ${ }^{37}$ The result of $\approx 0.2 \mu \mathrm{g} / \mathrm{g} \mathrm{Tl}$ for SRM 1646a has been confirmed by several independent techniques in our laboratory in the meantime, and is not in contradiction to the recommended value of $<0.5 \mu \mathrm{g} / \mathrm{g} \mathrm{Tl}$. This is obviously only one example, and the results of these experiments can certainly not be generalized, but it is at least an indication that CS AAS might well offer better conditions to also handle non-spectral interferences more reliably than has been possible with LS AAS. Future applications will show if this assumption is correct.

\section{Conclusions}

Besides the obvious advantage that only one radiation source is necessary for all elements, the high intensity of the $\mathrm{CS}$ provides roughly the same favorable $\mathrm{S} / \mathrm{N}$ ratio for all analytical lines, resulting in improved photometric precision and limits of detection. In combination with the linear CCD array detector, the CS offers unique diagnostic opportunities for method development and mechanistic studies in GFAAS, as it reveals the spectral environment of the analytical line over a range of approximately $\pm 0.15 \mathrm{~nm}$ at high resolution. The various possibilities to correct for background absorption, which may result from a dissociation continuum, an electron excitation spectrum with rotational fine structure, or from a concomitant element, reduce the risk of errors due to spectral interferences essentially to zero. Last but not least, there is a justified hope that even non-spectral interferences could be treated more easily, eliminating the need for modifiers through the use of 'fast furnace programs', resulting in more rugged analytical conditions than are available with LS AAS.

\section{Acknowledgements}

The authors are grateful to Conselho Nacional de Desenvolvimento Científico e Technológico (CNPq) for a research fellowship (B.W.). The authors are also grateful to

Table 2. Determination of thallium in marine sediment reference materials using solid sampling LS-GF AAS with Zeeman-effect background correction (Z AAS), ${ }^{39}$ and slurry sampling CS-GF AAS (CS AAS), ${ }^{36}$ respectively, without a chemical modifier using a pyrolysis temperature of $300{ }^{\circ} \mathrm{C}$ (No Modifier), and using a combination of $0.4 \mathrm{mg} \mathrm{Ru}$ as a permanent modifier and $5 \% \mathrm{w} / \mathrm{v} \mathrm{NH}_{4} \mathrm{NO}_{3}$ added in solution $\left(\mathrm{Ru}+\mathrm{NH}_{4} \mathrm{NO}_{3}\right.$ ). All values in $\mu \mathrm{g} / \mathrm{g}$; results are averages with standard deviation of at least $\mathrm{n}=3$ measurements

\begin{tabular}{lccccc}
\hline $\begin{array}{l}\text { Reference } \\
\text { Material }\end{array}$ & $\begin{array}{c}\text { Reference } \\
\text { Value }\end{array}$ & $\begin{array}{c}\text { Z AAS } \\
\text { No Modifier }\end{array}$ & $\begin{array}{c}\text { Z AAS } \\
\mathrm{Ru}^{2} \mathrm{NH}_{4} \mathrm{NO}_{3}\end{array}$ & $\begin{array}{c}\text { CS AAS } \\
\text { No Modifier }\end{array}$ & $\begin{array}{c}\text { CS AAS } \\
\mathrm{Ru}^{2} \mathrm{NH}_{4} \mathrm{NO}_{3}\end{array}$ \\
\hline BCSS $-1^{\mathrm{a}}$ & $(0.6)^{\mathrm{c}}$ & n.d. & $0.59 \pm 0.04$ & $0.51 \pm 0.04$ & $0.51 \pm 0.01$ \\
HISS $-1^{\mathrm{a}}$ & $(0.06)^{\mathrm{c}}$ & $0.02 \pm 0.002$ & $0.05 \pm 0.003$ & $0.054 \pm 0.01$ & $0.055 \pm 0.005$ \\
MESS $-1^{\mathrm{a}}$ & $(0.7)^{\mathrm{c}}$ & n.d. & $0.70 \pm 0.02$ & $0.57 \pm 0.01$ & $0.58 \pm 0.01$ \\
MESS $-2^{\mathrm{a}}$ & $(0.98)^{\mathrm{c}}$ & $0.19 \pm 0.01$ & $1.07 \pm 0.03$ & $0.98 \pm 0.02$ & $0.99 \pm 0.02$ \\
MESS $-3^{\mathrm{a}}$ & $0.90 \pm 0.06^{\mathrm{a}}$ & n.d. & $1.08 \pm 0.07$ & $0.93 \pm 0.04$ & $1.02 \pm 0.015$ \\
PACS $-2^{\mathrm{a}}$ & $(0.6)^{\mathrm{c}}$ & $0.12 \pm 0.03$ & $0.58 \pm 0.02$ & $0.50 \pm 0.01$ & $0.52 \pm 0.005$ \\
SRM $1646 \mathrm{a}^{\mathrm{b}}$ & $(<0.5)^{\mathrm{c}}$ & n.d. & $0.20 \pm 0.02$ & $0.20 \pm 0.02$ & $0.17 \pm 0.01$ \\
\hline
\end{tabular}

a National Research Council Canada, Ottawa, Ontario, Canada; ${ }^{\mathrm{b}}$ National Institute of Standards and Technology, Gaithersburgh, MD, USA; ${ }^{\mathrm{a}}$ Information value, not certified; ${ }^{\mathrm{d}}$ Certified value and $95 \%$ confidence interval; ${ }^{\mathrm{e}}$ n.d. $=$ not determined. 
Harald Berndt, ISAS Dortmund, Germany, who provided the drawing in Figure 9 from the legacy of Hans Massman.

\section{References}

1. Kirchhoff, G.; Poggendorf's Ann. Physik 1860, 109, 275.

2. Kirchhoff, G.; Bunsen, R.; Phil. Mag.1860, 20, 89.

3. Lockyer, J.N.; Studies in Spectrum Analysis, Appleton: London, 1878.

4. Walsh, A.; Anal. Chem. 1974, 46, 698 A.

5. Walsh, A.; Spectrochim. Acta 1955, 7, 108.

6. Koirtyohann, S.R.; Pickett, E.E.; Anal. Chem. 1965, 37, 601.

7. Harnly, J.M.; J Anal. At. Spectrom. 1999, 14, 137.

8. Fassel, V.A.; Mossotti, V.G.; Grossman, W.E.; Knisely, R.N.; Spectrochim. Acta Part B 1966, 22, 347.

9. McGee, W.W.; Winefordner, J.D.; Anal. Chem. 1967, 37, 429.

10. Nitis, J.G.; Svoboda, V.; Winefordner, J.D.; Spectrochim. Acta Part B 1972, 27, 345.

11. Veillon, C.; Merchant, P.; Appl. Spectrosc. 1973, 27, 361.

12. Keliher, P.N.; Wohlers, C.C.; Anal. Chem. 1974, 46, 682.

13. Zander, A.T.; O'Haver, T.C.; Keliher, P.; Anal. Chem. 1976, 48, 1166.

14. Harnly, J.M.; O’Haver, T.C.; Golden, B.; Wolf, W.R.; Anal. Chem. 1979, 51, 2007.

15. Harnly, J.M.; J. Anal. At. Spectrom. 1993, 8, 317.

16. Harnly, J.M.; Smith, C.M.M.; Wichems, D.N.; Ivaldi, J.C.; Lundberg, P.L.; Radziuk, B.; J. Anal. At. Spectrom. 1997, 12, 617.

17. Schuetz, M.; Murphy, J.; Fields, R.E.; Harnly, J.M.; Spectrochim. Acta Part B 2000, 55, 1895.

18. Snelleman, W.; Spectrochim. Acta Part B 1968, 23, 403.

19. Elser, R.C.; Winefordner, J.D.; Anal. Chem. 1972, 44, 698.

20. Hieftje, G.M.; J. Anal.At. Spectrom. 1989, 4, 117.

21. Florek, S.; Becker-Ross, H. In CANAS '93 Colloquium Analytische Atomspektroskopie; Welz, B., ed.; Bodenseewerk Perkin-Elmer: Überlingen 1993, p.853.

22. Becker-Ross, H.; Florek, S. In CANAS '95 Colloquium Analytische Atomspektroskopie; Welz, B., ed.; Bodenseewerk Perkin-Elmer: Überlingen 1996, p.1.

23. Florek, S.; Becker-Ross, H.; Florek, T.; Fresenius J. Anal. Chem. 1996, 355, 269.
24. Becker-Ross, H.; Florek, S.; Heitmann, U.; Weisse, R.; Fresenius J. Anal. Chem. 1996, 355, 300.

25. Heitmann, U.; Schütz, M.; Becker-Ross, H.; Florek, S.; Spectrochim. Acta Part B 1996, 51, 1095.

26. Becker-Ross, H.; Florek, S.V.; Spectrochim. Acta Part B 1997, 52, 1367.

27. Becker-Ross, H.; Florek, S.; Heitmann, U.; J. Anal. At. Spectrom. 2000, 15, 137.

28. Florek, S.; Becker-Ross, H.; J. Anal. At. Spectrom. 1995, 10, 145.

29. Pilon, M.J.; Denton, M.B.; Schleicher, R.G.; Moran, P.M.; Smith, S.B.; Appl. Spectrosc. 1990, 44, 1613.

30. Barnard, T.W.; Crochett, M.J.; Ivaldi, J.C.; Lundberg, P.L.; Anal. Chem. 1993, 65, 1225.

31. Barnard, T.W.; Crockett, M.J.; Ivaldi, J.C.; Lundberg, P.L.; Yates, D.A.; Levine, P.A.; Sauer, D.J.; Anal. Chem. 1993, 65, 1231.

32. Welz, B.; Sperling, M.; Atomic Absorption Spectrometry, $3^{\text {rd }}$ ed., Wiley-VCH: Weinheim, New York, 1999.

33. Zaidel, A.N.; Korennoi, E.P.; Opt. Spectrosc. 1961, 10, 299.

34. Goleb, J.A.; Yokoyama, Y.; Anal. Chim. Acta 1964, 30, 213.

35. Räde, H.S.; At. Absorpt. Newslett. 1974, 13, 81.

36. Chapman, J.F.; Dale, L.S.; Fraser, H.J.; Anal. Chim. Acta 1980, 116, 427.

37. Welz, B.; Vale, M.G.R.; Silva, M.M.; Becker-Ross, H.; Huang, M.D.; Florek, S.; Heitmann, U.; Spectrochim. Acta Part B 2002, 57, 1043.

38. Smith, S.B.; Hieftje, G.M.; Appl. Spectrosc. 1983, 37, 419.

39. Vale, M.G.R.; Silva, M.M.; Welz, B.; Nowka, R.; J. Anal.At. Spectrom. 2002, 17, 38.

40. Slavin, W.; Manning, D.C.; Carnrick, G.R.; At. Spectrosc. 1981, 2, 137.

41. Welz, B.; Vale, M.G.R.; Spectrochim. Acta Part B 2002, 57, in the press.

42. Manning, D.C.; Slavin, W.; Spectrochim. Acta Part B 1988, 43, 1157 .
Received: October 19, 2002

Published on the web: April 11, 2003 